\title{
A Comparative Study on Antimicrobial Efficacy of A Novel Irrigant, Nigella Sativa Oil Against Enterococcus Faecalis (ATCC 29212)- A Preliminary Study.
}

Neha Jain, MDS ${ }^{1 *}$, Kiran Kumar N, MDS ${ }^{2}$, Savitha B Naik, MDS ${ }^{3}$, Seema Merwade, MDS ${ }^{4}, B_{i j i}$ Brigit, MDS $^{5}, K$ Rashmi, MDS $^{6}$

${ }^{1}$ Senior Lecturer, KLE Society's Institute of Dental Sciences, Bengaluru, India

${ }^{2}$ Professor \& Head of Department, Government Dental College \& Research Institute, Bengaluru, Karnataka, India

${ }^{3-5}$ Associate Professor, Government Dental College \& Research Institute, Bengaluru, Karnataka, India

${ }^{6}$ Assistant Professor, Government Dental College \& Research Institute, Bengaluru, Karnataka, India

\author{
DOI: $10.36348 /$ SJODR.2019.v04i09.004 \\ | Received: 26.08.2019| Accepted: 16.09.2019| Published: 20.09.2019 \\ *Corresponding author: Neha Jain
}

\section{Abstract}

Mechanical enlargement of the root canals must be accompanied by copious irrigation of specific irrigants that can render the prepared canal as bacteria-free as possible. The use of herbal alternatives has become the dernier cri owing to the increase in antibiotic resistance against chemical medications. No study has been performed to check the antimicrobial activity of Nigella sativa oil against the persistent endodontic pathogen, E. faecalis \& hence this preliminary study aims to compare the antibacterial potency of Nigella sativa oil against E. faecalis and compare it with $2.5 \%$ sodium hypochlorite. Nigella sativa oil and 2.5\% Sodium Hypochlorite were tested against Enterococcus faecalis-ATCC 29212 to check for their Minimum Inhibitory Concentration (MIC) by double dilution method and Mean Kill Time as a measure of their antimicrobial potency to be used as an intracanal irrigant. The results show that Nigella sativa oil has a MIC of $0.4 \mu \mathrm{l} / \mathrm{ml}$ while $2.5 \%$ sodium hypochlorite has a MIC of $50 \mu \mathrm{l} / \mathrm{ml}$ against E. faecalis. Nigella sativa oil has bactericidal effects by $30 \mathrm{mins}$ of its exposure to E. faecalis while $2.5 \%$ sodium hypochlorite showed reduced growth of E. faecalis at the end of two-hour exposure. Under the limitations of this study, it was concluded that Nigella sativa seed oil has a better antimicrobial effect than $2.5 \%$ sodium hypochlorite against $E$. faecalis

Keywords: Antimicrobial, E. faecalis ATCC 29212, Mean Kill Time, Minimum Inhibitory Concentration, Nigella sativa, $2.5 \%$ Sodium hypochlorite.

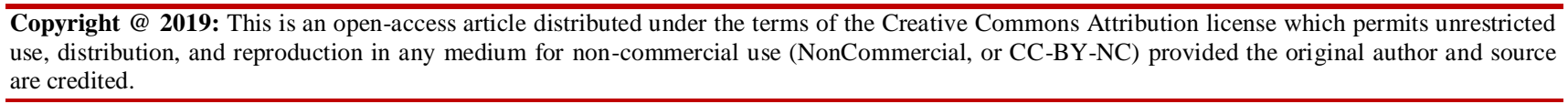

\section{INTRODUCTION}

The most alluring purpose of endodontic therapy has been to eliminate infectious agents or to considerably reduce the microbial burden from the root canal and to prevent re-infection by ensuring a fluid tight seal. Dental pulp anatomy is bewildering due to the presence of fins, isthmus, intercanal communications and cul de sacs. These areas provide a serum filled and necrotic tissue loaded medium and our superbug- E. faecalis flourishes in this medium.

The prevalence of E. faecalis in asymptomatic persistent endodontic infection spans from 24 to $77 \%$. It plays a crucial role in the aetiology of persistent periradicular lesions. It forms majority of the bacteria present in endodontic failures and it also survives in the root canal as a single organism [1]. The highly complex nature of the organism poses a great threat to the skills of an endodontist.

Mechanical enlargement of the root canals must be assisted by copious irrigation of specific irrigants that can render the prepared canal as pristine as possible.

Root canal irrigants, includes chelating agent (ethylene diaminetetraacetic acid EDTA), acids (citric and phosphoric), alkaline solutions (sodium hypochlorite, sodium hydroxide, urea, and potassium hydroxide), proteolytic enzymes, oxidative agents (hydrogen peroxide and Gly-Oxide). Recently, herbal irrigants like triphala, green tea polyphenols have been tested [2]. 
Neha Jain et al; Saudi J Oral Dent Res, Sep 2019; 4(9): 584-588

Sodium hypochlorite $(\mathrm{NaOCl})$, is the routinely used irrigating solution. Inadvertent extrusion during the irrigation causes severe caustic effects and cytotoxicity on the adjacent healthy tissues. Thus, a lower concentration $0.5-1 \%$ or $2.5 \% \mathrm{NaOC} 1$ is more commonly preferred by clinicians [3]

The use of herbal alternatives has become the dernier cri owing to the increase in antibiotic resistance against chemical medications.

Nigella sativa (N. sativa) (NS) (Family Ranunculaceae) is rising as a miracle herb with a plenteous historical and religious background. NS is also known as black seed. Its main bioactive component is Thymoquinone (TQ)[4].

The literature on the therapeutic potential of NS in endodontics is scarce, but its miraculous powers are very tempting and needs to be explored. No study has been performed to check the antimicrobial activity of nigella sativa against $E$. faecalis \& hence this preliminary study aims to compare the antibacterial potency of Nigella sativa oil against E. faecalis and compare it with $2.5 \%$ sodium hypochlorite.

\section{MATERIALS \& METHODOLOGY}

Material: Strains of E. faecalis- ATCC 29212 (procured from Maratha Mandal's Central Research Laboratory, Belgaum), Essential Pure Black Seed Oil (100\% cold pressed by Amazing Herbs, U.S.A), 2.5\% Sodium Hypochlorite. Culture media: Brain Heart Infusion broth (HIMEDIA M210-500G)
Minimum Inhibitory Concentration (MIC) Test (Aerobic): [5]

It was performed using double dilution method. 9 dilutions of each drug were done with BHI for MIC. In the initial tube $20 \mu \mathrm{l}$ of drug was added into the $380 \mu \mathrm{l}$ of BHI broth. For dilutions $200 \mu \mathrm{l}$ of BHI broth was added into the next 9 tubes separately. Then from the initial tube $200 \mu \mathrm{l}$ was transferred to the first tube containing $200 \mu \mathrm{l}$ of BHI broth. This was considered as 10:2 dilutions. From 10:2 diluted tube $200 \mu \mathrm{l}$ was transferred to second tube to make 10:2 dilution. The serial dilution was repeated up to 10:9 dilutions for each drug. From the maintained stock cultures of required organisms, $5 \mu \mathrm{l}$ was taken and added into $2 \mathrm{ml}$ of BHI (brain heart infusion) broth. In each serially diluted tube $200 \mu \mathrm{l}$ of above culture suspension was added. The tubes were incubated for 24 hours and observed for turbidity.

\section{Time Kill Curve:[5]}

An equal quantity of the broth with organism and compound was mixed then immediately it was plated, this was noted as $0 \mathrm{hrs}$. Tubes were kept in $\mathrm{CO} 2$ jar till further time slot. After time interval of $5 \mathrm{mins}$, $10 \mathrm{mins}$, 30mins and $2 \mathrm{hrs}$, it was plated and kept in the $\mathrm{CO} 2$ Jar (anaerobic jar). After 48-72 hrs of incubation the plates were removed and the colony count was noted. The above-mentioned tests were performed in triplicate to avoid bias in results.

\section{RESULTS}

Table 1: Minimum Inhibitory Concentrations:

Table 2: Time kill curve:

Legend 1

Table-1: Minimum Inhibitory Concentration Results

\begin{tabular}{|l|l|l|l|l|l|l|l|l|l|l|l|}
\hline $\begin{array}{l}\text { SI } \\
\text { No. }\end{array}$ & Samples & $\begin{array}{l}\mathbf{1 0 0} \\
\boldsymbol{\mu l} / \mathbf{m l}\end{array}$ & $\begin{array}{l}\mathbf{5 0} \\
\boldsymbol{\mu l} / \mathbf{m l}\end{array}$ & $\begin{array}{l}\mathbf{2 5} \\
\boldsymbol{\mu l} / \mathbf{m l}\end{array}$ & $\begin{array}{l}\mathbf{1 2 . 5} \\
\boldsymbol{\mu l} / \mathbf{m l}\end{array}$ & $\begin{array}{l}\mathbf{6 . 2 5} \\
\boldsymbol{\mu l} / \mathbf{m l}\end{array}$ & $\begin{array}{l}\mathbf{3 . 1 2} \\
\boldsymbol{\mu l} / \mathbf{m l}\end{array}$ & $\begin{array}{l}\mathbf{1 . 6} \\
\mathbf{s} \boldsymbol{\mu l} / \mathbf{m l}\end{array}$ & $\begin{array}{l}\mathbf{0 . 8} \\
\boldsymbol{\mu l} / \mathbf{m l}\end{array}$ & $\begin{array}{l}\mathbf{0 . 4} \\
\boldsymbol{\mu l} / \mathbf{m l}\end{array}$ & $\begin{array}{l}\mathbf{0 . 2} \\
\boldsymbol{\mu l} / \mathbf{m l}\end{array}$ \\
\hline & $\begin{array}{l}\text { E. faecalis } \\
\text { ATCC 29212 }\end{array}$ & & & & & & & & & & \\
\hline 01 & Nigella sativa oil & $\mathrm{S}$ & $\mathrm{S}$ & $\mathrm{S}$ & $\mathrm{S}$ & $\mathrm{S}$ & $\mathrm{S}$ & $\mathrm{S}$ & $\mathrm{S}$ & $\mathrm{S}$ & $\mathrm{R}$ \\
\hline 02 & $2.5 \% \mathrm{NaOCl}$ & $\mathrm{S}$ & $\mathrm{S}$ & $\mathrm{R}$ & $\mathrm{R}$ & $\mathrm{R}$ & $\mathrm{R}$ & $\mathrm{R}$ & $\mathrm{R}$ & $\mathrm{R}$ & $\mathrm{R}$ \\
\hline & & & & & & & & & & & \\
\hline 01 & Nigella sativa oil & $\mathrm{S}$ & $\mathrm{S}$ & $\mathrm{S}$ & $\mathrm{S}$ & $\mathrm{S}$ & $\mathrm{S}$ & $\mathrm{S}$ & $\mathrm{S}$ & $\mathrm{R}$ & $\mathrm{R}$ \\
\hline 02 & $2.5 \% \mathrm{NaOCl}$ & $\mathrm{S}$ & $\mathrm{S}$ & $\mathrm{R}$ & $\mathrm{R}$ & $\mathrm{R}$ & $\mathrm{R}$ & $\mathrm{R}$ & $\mathrm{R}$ & $\mathrm{R}$ & $\mathrm{R}$ \\
\hline & & & & & & & & & & & \\
\hline 01 & Nigella sativa oil & $\mathrm{S}$ & $\mathrm{S}$ & $\mathrm{S}$ & $\mathrm{S}$ & $\mathrm{S}$ & $\mathrm{S}$ & $\mathrm{S}$ & $\mathrm{S}$ & $\mathrm{S}$ & $\mathrm{R}$ \\
\hline 02 & $2.5 \% \mathrm{NaOCl}$ & $\mathrm{S}$ & $\mathrm{S}$ & $\mathrm{R}$ & $\mathrm{R}$ & $\mathrm{R}$ & $\mathrm{R}$ & $\mathrm{R}$ & $\mathrm{R}$ & $\mathrm{R}$ & $\mathrm{R}$ \\
\hline
\end{tabular}

Table-2: Time Kill Curve Results

\begin{tabular}{|l|l|l|l|l|l|l|}
\hline SI No. & Samples & 00 Hrs & 05 Min & 10 Min & 30 Min & 02 Hrs \\
\hline & E. faecalis: ATCC 29212 & & & & & \\
\hline 01 & Nigella sativa oil & 78 & 70 & 32 & NG & NG \\
\hline 02 & $2.5 \% \mathrm{NaOCl}$ & 102 & 96 & 84 & 72 & 70 \\
\hline & & & & & & \\
\hline 01 & Nigella sativa oil & 70 & 69 & 34 & NG & NG \\
\hline 02 & $2.5 \% \mathrm{NaOCl}$ & 100 & 94 & 80 & 61 & 58 \\
\hline & & & & & & \\
\hline 01 & Nigella sativa oil & 74 & 68 & 31 & NG & NG \\
\hline 02 & $2.5 \% \mathrm{NaOCl}$ & 98 & 92 & 81 & 60 & 54 \\
\hline
\end{tabular}

Legend $1 \mathrm{NaOCl}$ - Sodium Hypochlorite S- Sensitive R-Resistant NG- No Growth 


\section{DISCUSSION}

The leading cause of failed endodontic therapy is the survival of microorganisms in the apical third of the root [1]. Bacteria and their by-products form a microbial biofilm which adheres to dentinal walls in the infected root canals [6]. Bacterial biofilms are reported to be the most common cause of persistent inflammation. The morphology of root canal systems is complex and this favours growth of bacteria in the form of biofilms [7].

Enterococcus faecalis is a gram-positive coccus, facultative anaerobe. It can gain access to the root canal system during treatment, between appointments, or even after the treatment has been completed. It withstands extended spells of nutritional impoverishment, it binds to dentin and invades the dentinal tubules, forms a biofilm, alters host responses, decreases the action of lymphocytes, possesses lytic enzymes, uses serum as a nutritional source, resists intracanal medicaments like $\mathrm{Ca}(\mathrm{OH})_{2},[8]$ which makes its complete elimination challenging.

An ideal root canal irrigant should have antimicrobial activity, should dissolve remnants of pulp tissue, lubricate during mechanical instrumentation, be easily available and be inexpensive. None of the root canal irrigant used so far is ideal, thus the hunt for new irrigation solutions is still on [9].

Sodium hypochlorite $(\mathrm{NaOCl})$, is most widely used irrigating solution. It was used as an irrigant in early 1919 as recommended by Coolidge. It removes the organic component of pulp, has a varying antibacterial action, dissolves the necrotic tissue, is cheap, easily available and has a good shelf life [10]. $5.25 \%$ concentration was the most effective solution followed by $2.5 \%$ concentration. It does not remove the endodontic smear layer. It has an unpleasant taste, tends to bleach clothes and it is potentially corrosive. Inadvertent extrusion during the irrigating procedure causes hypochlorite accidents as it is cytotoxic and caustic on healthy periradicular tissues. Such sodium hypochlorite accidents are the reason for lower concentration $0.5-1 \%$ or $2.5 \%$ being more commonly preferred by clinicians [3, 10]. Studies have demonstrated that $40-60 \%$ of the root canals still have detectable levels of cultivable bacteria after chemomechanical procedures using $\mathrm{NaOCl}$ as the irrigant[11].

Owing to cytotoxic effects of $\mathrm{NaOCl} \&$ increasing antibiotic resistance, there is a constant hunt for safer, herbal irrigant.

Nigella sativa is among the top ranked herb and is called as the "Miracle Herb of the Century". It possesses an extensive scope of activities like as analgesic, antimicrobial, and anti-inflammatory, diuretic, antihypertensive, antidiabetic, antioxidant, anticancer and immunomodulatory, anthelmintic, gastroprotective, spasmolytic, bronchodilator, hepatoprotective, renal protective properties [4].

During the investigation of the MIC of both the Nigella sativa oil and $2.5 \%$ Sodium Hypochlorite solution, E. faecalis strains were sensitive to the black seed oil until the $9^{\text {th }}$ dilution $(0.4 \mu \mathrm{l} / \mathrm{ml})$ while the $E$. faecalis strains were sensitive to $2.5 \%$ sodium hypochlorite until the $2^{\text {nd }}$ dilution $(50 \mu \mathrm{l} / \mathrm{ml})$ only. Lower MIC values of black cumin seed oils against the E. faecalis species is indicative of its high degree of effectiveness against these pathogens. Time kill curve shows absolutely no growth at the $30^{\text {th }}$ minute onwards for the Nigella sativa oil while there was growth present until the second hour for the specimens tested against $2.5 \%$ sodium hypochlorite. While studying the microbicidal/micro biostatic nature of these agents, Nigella sativa oil was reported to be microbicidal, while $2.5 \%$ sodium hypochlorite solution demonstrated reduced growth of E. faecalis.

Based on other studies it can be deducted that the following could be the possible reasons for incomplete elimination of E. faecalis using $2.5 \%$ sodium hypochlorite:

Berber et al. evaluated the efficacy of $0.5 \%$, $2.5 \%$ and $5.25 \% \mathrm{NaOCl}$ as intracanal irrigants against E. faecalis. They concluded that $5.25 \%$ concentration was the most effective solution followed by $2.5 \%$ concentration. High concentrations are associated with cytotoxic and caustic reactions; hence a lower concentration of $2.5 \%$ of $\mathrm{NaOCl}$ was used in our study. Siqueira et al. assessed the bacterial reduction after instrumentation using $2.5 \% \mathrm{NaOCl}$ as an irrigant. Results showed that chemo mechanical preparation with $2.5 \% \mathrm{NaOCl}$ remarkably reduced the number of bacteria in the canal but failed to render the canal free of cultivable bacteria in more than one-half of the cases [10], which supports the results concluded by our study. The persistence of E. faecalis in endodontic infection might be aided by an enhanced resistance to sodium hypochlorite [12]. Its antimicrobial property is proportional to the drug concentration, as well as its toxicity. With the reduced working time made possible by the advent of rotary instruments and techniques for root canal preparation, the irrigant of choice should be one that exerts its microbial activity quickly against resistant microorganisms found in the root canal and dentinal tubules, such as E. faecalis [11]. Nigella sativa has several active components including thymoquinone (TQ), thymohydroquinone, dithymoquinone, thymol, carvacrol, nigellimine-N-oxide, nigellicine, nigellidine, and alphahederin [13].

Based on other studies it can be hypothesised that the following could be the mode of action of NS. Studies show that TQ is the major bioactive component 
and a volatile oil of NS [14]. It prevents bacterial biofilm formation by reducing the metabolic oxidative activity of E. faecalis \& prevents cell adhesion to glass slide surfaces [9]. It also has been shown to prevent the attachment of bacteria to host tissues [15]. It has selective antimicrobial property which is effective against Gram positive bacteria. Multi drug resistant bacteria generally possess a pump efflux which is inhibited by NS, leading to the accumulation of the antibiotic in the bacterial cell [16].

Its added benefits include: its candidacidal activity [17], it is a powerful anti-oxidant [18], it has immune-potentiating activity [17], it also induces minimal inflammatory response and keeps the pulp vital or capable of repair [19]. NS has been shown to reduce the microbial flora of the infected root canals significantly. TQ, has an antibacterial activity and antibiotics could potentiate its activity [14]. The antiinflammatory features of $N$. sativa are by inhibiting histamine release from mast cells [20].

Increased contact time could lead to increased antimicrobial activity. With regards to the safety of Nigella sativa, the seeds' powder did not produce any toxic effects at very high doses $(28 \mathrm{~g} / \mathrm{kg})$ when given orally to rabbits. Its oil was also very safe when given orally to rats (LD50 of $28.8 \mathrm{mg} / \mathrm{kg}$ ) [21]. Administration of either the seed extract or its oil has been shown not to induce significant adverse effects on liver or kidney functions [22]. The bioactive compounds of medicinal plants have low toxicity and $\mathrm{N}$. sativa is a promising and a significant source of diverse types of bioactive ingredients [23].

Black cumin is inexpensive and widely available [7] and has a long track record in traditional medicine. Recently, it has been used for treatment of several disorders without any reported side effects [24] and hence it is considered a biologically accepted material.

\section{CONCLUSION}

According to the results obtained Nigella sativa oil proves to have a better antimicrobial activity than $2.5 \%$ Sodium hypochlorite against E. faecalis. This can be considered as a preliminary study as Nigella sativa oil has never been tested against E. faecalis strains.

However, translation of this study on tooth models, preclinical and clinical trials are required. Studies at the cellular and molecular levels to investigate the exact mechanism of action of NS and TQ, before black cumin seed oil can be conclusively be recommended as an intra- canal irrigating solution. The antimicrobial action of Nigella sativa oil appears promising.

\section{ACKNOWLEDGEMENT}

We would like to thank Dr. Kishore G. Bhat and his team at Maratha Mandal's Central Research Laboratory, Belgaum, for conducting the microbial analysis of the study. The authors deny any conflicts of interest. We have no financial affiliation. The study was presented and awarded the best paper in IACDE 1st Zonal Conference (South) Chennai, Tamil Nadu, India on 11.08.2018.

\section{REFERENCES}

1. Stuart, C. H., Schwartz, S. A., Beeson, T. J., \& Owatz, C. B. (2006). Enterococcus faecalis: its role in root canal treatment failure and current concepts in retreatment. Journal of endodontics, 32(2), 9398.

2. Thakur, S. (2016). Root Canal Irrigants in Horizon: A Review. International Journal of Science and Research, 5(3), 1240-3.

3. Chandra, S.B., Gopikrishna, V. Grossman's Endodontic Practice. In: Irrigants and Intracanal Medicaments. $13^{\text {th }}$ edition. Wolters Kluwer (India) Pvt. Ltd. 327-329.

4. Ahmad, A., Husain, A., Mujeeb, M., Khan, S. A., Najmi, A. K., Siddique, N. A., \& Anwar, F. (2013). A review on therapeutic potential of Nigella sativa: A miracle herb. Asian Pacific journal of tropical biomedicine, 3(5), 337-352.

5. Schwalbe, R., Steele-Moore, L., \& Goodwin, A. C. (2007). Antimicrobial susceptibility testing protocols. Crc Press.

6. Mikić, I. M., Cigić, L., Kero, D., Govorko, D. K., Mehičić, G. P., \& Simeon, P. (2018). Antimicrobial effectiveness of polyhexamethylene biguanide on Enterococcus faecalis, Staphylococcus epidermidis and Candida albicans. Medicinski Glasnik, 15(2).

7. Peciuliene, V., Maneliene, R., Balcikonyte, E., Drukteinis, S., \& Rutkunas, V. (2008). Microorganisms in root canal infections: a review. Stomatologija, 10(1), 4-9.

8. Hedge, V. (2009). Enterococcus faecalis: Clinical significance and treatment considerations. Endodontology, 21(2), 48-52.

9. Kokoska, L., Havlik, J., Valterova, I., Sovova, H., Sajfrtova, M., \& Jankovska, I. (2008). Comparison of chemical composition and antibacterial activity of Nigella sativa seed essential oils obtained by different extraction methods. Journal of food protection, 71(12), 2475-2480.

10. Mohammadi, Z. (2008). Sodium hypochlorite in endodontics: an update review. International dental journal, 58(6), 329-341.

11. Berber, V. B., Gomes, B. P. F. A., Sena, N. T., Vianna, M. E., Ferraz, C. C. R., Zaia, A. A., \& Souza-Filho, F. J. (2006). Efficacy of various concentrations of $\mathrm{NaOCl}$ and instrumentation techniques in reducing Enterococcus faecalis within root canals and dentinal 
tubules. International endodontic journal,39(1), 10-17.

12. Radcliffe, C. E., Potouridou, L., Qureshi, R., Habahbeh, N., Qualtrough, A., Worthington, H., \& Drucker, D. B. (2004). Antimicrobial activity of varying concentrations of sodium hypochlorite on the endodontic microorganisms Actinomyces israelii, A. naeslundii, Candida albicans and Enterococcus faecalis. International endodontic journal, 37(7), 438-446.

13. Randhawa, M. A., \& Alghamdi, M. S. (2011). Anticancer activity of Nigella sativa (black seed) a review. The American journal of Chinese medicine, 39(06), 1075-1091.

14. Omar, O. M., Khattab, N. M., \& Khater, D. S. (2012). Nigella sativa oil as a pulp medicament for pulpotomized teeth: A histopathological evaluation. Journal of Clinical Pediatric Dentistry, 36(4), 335-341.

15. Hull, S. V., Benghuzzi, H., \& Tucci, M. (2010). Inhibition of bacterial attachment to kidney epithelial cells using thymoquinone-biomed 2010. Biomedical sciences instrumentation, 46, 6974.

16. Kouidhi, B., Zmantar, T., Jrah, H., Souiden, Y., Chaieb, K., Mahdouani, K., \& Bakhrouf, A. (2011). Antibacterial and resistance-modifying activities of thymoquinone against oral pathogens. Annals of clinical microbiology and antimicrobials, 10(1), 29.

17. Khan, M. A. U., Ashfaq, M. K., Zuberi, H. S., Mahmood, M. S., \& Gilani, A. H. (2003). The in vivo antifungal activity of the aqueous extract from Nigella sativa seeds. Phytotherapy Research: An
International Journal Devoted to Pharmacological and Toxicological Evaluation of Natural Product Derivatives, 17(2), 183-186.

18. Akhondian, J., Kianifar, H., Raoofziaee, M., Moayedpour, A., Toosi, M. B., \& Khajedaluee, M. (2011). The effect of thymoquinone on intractable pediatric seizures (pilot study). Epilepsy research, 93(1), 39-43.

19. AlAttas, S. A., Fat'heya, M. Z., \& Turkistany, S. A. (2016). Nigella sativa and its active constituent thymoquinone in oral health. Saudi medical journal, 37(3), 235.

20. Ikhsan, M., Hiedayati, N., Maeyama, K., \& Nurwidya, F. (2018). Nigella sativa as an antiinflammatory agent in asthma. BMC research notes, 11(1), 744 .

21. Zaoui, A., Cherrah, Y., Mahassini, N., Alaoui, K., Amarouch, H., \& Hassar, M. (2002). Acute and chronic toxicity of Nigella sativa fixed oil. Phytomedicine, 9(1), 69-74.

22. Salem, M. L. (2005). Immunomodulatory and therapeutic properties of the Nigella sativa L. seed. International immunopharmacology, 5(1314), 1749-1770.

23. Imran, M., Rauf, A., Khan, I. A., Shahbaz, M., Qaisrani, T. B., Fatmawati, S., \& Gondal, T. A. (2018). Thymoquinone: A novel strategy to combat cancer: A review. Biomedicine \& Pharmacotherapy, 106, 390-402.

24. Oskouei, Z., Akaberi, M., \& Hosseinzadeh, H. (2018). A glance at black cumin (Nigella sativa) and its active constituent, thymoquinone, in ischemia: a review. Iranian journal of basic medical sciences, 21(12), 1200. 